\title{
The Context of Transport in the Concept of the Syndromes of Global Change
}

\author{
K. Neubergová \\ Department of transport systems, Faculty of Transportation Sciences , Czech Technical University in Prague, \\ Prague, Czech Republic \\ Corresponding authors: neubergova@fd.cvut.cz
}

DOI: $10.2478 / v 10158-010-0013-1$

\begin{abstract}
This contribution aims at outlining the relatively new approach towards the issue of the global changes assessment. Firstly the Concept of the syndromes of global change is presented. This Concept brought a new view to the human-made impacts assessment. The second part of this paper discusses the role of transport in the constituent elements of this Concept. Transport plays an overriding role in development syndromes, primarily in the Urban Sprawl Syndrome.
\end{abstract}

KEY WORDS: Transport, global change, suburbanization, pollution.

\section{INTRODUCTION}

There are many factors which shape our environment and human-made impacts play a crucial part at this time. Human activities have always influenced environment but nowadays is the first time when these impacts have a global scale. The anthropogenic climate change is a good example to show the dimension of human-made effects. One of the human activities especially causing climate change is transport. Transport is influenced by economic and social development, but also brings with it a lot of undesirable impacts, such noise and air pollution, etc.

\section{CONCEPT OF THE SYNDROMES OF GLOBAL CHANGE}

The Concept of the syndromes of global change was developed by the German Advisory Council on Global Change (WGBU) in 1996. Global Change is clearly about to transform the operational mode of the global ecosystem, thereby generating cascades of significant (and possibly irreversible) impacts on the majority of individuals in present and future generations (WGBU, 1996). Firstly, the WGBU described - with force symptoms - the global dynamics with the aspects connected to the civilization - nature interface. Secondly, 16 syndromes were defined within the frame of the Concept divided into three categories (see table 1 (WGBU, 1996)).

The first category covers utilization syndromes, such as over-cultivation, overexploitation, non-sustainable agro-industrial use of soils and environmental destruction. The second category contains development syndromes, for example environmental degradation through uncontrolled urban growth, or the destruction of landscapes through the planned expansion of urban infrastructures. The last category of this Concept includes sink syndromes such as Smokestack Syndrome or Contaminated Land Syndrome. 
Table 1: Syndromes of Global Change (WGBU, 1996).

\begin{tabular}{|c|c|}
\hline Syndromes & Description \\
\hline \multicolumn{2}{|l|}{ Utilization Syndromes } \\
\hline Sahel syndrome & Over-cultivation of marginal land \\
\hline Overexploitation Syndrome & Overexploitation of natural ecosystems \\
\hline Rural Exodus Syndrome & $\begin{array}{l}\text { Environmental degradation through } \\
\text { abandonment of traditional agricultural } \\
\text { practices }\end{array}$ \\
\hline Dust Bowl Syndrome & $\begin{array}{l}\text { Non-sustainable agro-industrial use of soils } \\
\text { and bodies of water }\end{array}$ \\
\hline Katanga Syndrome & $\begin{array}{l}\text { Environmental degradation through depletion } \\
\text { of non-renewable resources }\end{array}$ \\
\hline Mass Tourism Syndrome & $\begin{array}{l}\text { Development and destruction of nature } \\
\text { for recreational ends }\end{array}$ \\
\hline Scorched Earth Syndrome & $\begin{array}{l}\text { Environmental destruction through war } \\
\text { and military action }\end{array}$ \\
\hline \multicolumn{2}{|l|}{ Development Syndromes } \\
\hline Aral Sea Syndrome & $\begin{array}{l}\text { Environmental damage of natural landscapes } \\
\text { as a result of large-scale projects }\end{array}$ \\
\hline Green Revolution Syndrome & $\begin{array}{l}\text { Environmental degradation through } \\
\text { the introduction of inappropriate farming } \\
\text { methods }\end{array}$ \\
\hline Asian Tigers Syndrome & $\begin{array}{l}\text { Disregard for environmental standards } \\
\text { in the course of rapid economic growth }\end{array}$ \\
\hline Favela Syndrome & $\begin{array}{l}\text { Environmental degradation through } \\
\text { uncontrolled urban growth }\end{array}$ \\
\hline Urban Sprawl Syndrome & $\begin{array}{l}\text { Destruction of landscapes through planned } \\
\text { expansion of urban infrastructures }\end{array}$ \\
\hline Major Accident Syndrome & $\begin{array}{l}\text { Singular anthropogenic environmental } \\
\text { disasters with long-term impacts }\end{array}$ \\
\hline \multicolumn{2}{|l|}{ Sink Syndromes } \\
\hline Smokestack Syndrome & $\begin{array}{l}\text { Environmental degradation through large } \\
\text { scale diffusion of long-lived substances }\end{array}$ \\
\hline Waste Dumping Syndrome & $\begin{array}{l}\text { Environmental degradation through } \\
\text { controlled and uncontrolled disposal of waste }\end{array}$ \\
\hline Contaminated Land Syndrome & $\begin{array}{l}\text { Local contamination of environmental assets } \\
\text { at industrial locations }\end{array}$ \\
\hline
\end{tabular}

For Global change analysis it is essential to assess not only single syndromes, but also their symptoms and interactions. Symptoms indicate both quantitative and qualitative changes of the Earth System. Interaction shows the connection of syndromes. There are six types of pairing among syndromes. The weakest, but most frequent, form is Coincidence. This form means that syndromes occur simultaneously. A stronger form is Coupling through common symptoms (several syndromes have common symptoms). The next form is Reinforcement. Symptoms could reinforce each other, as well as possibly reinforcing entire syndromes. Syndromes could also be allied through Attenuation or Infection. In the first case, one syndrome can whittle away another - for example, Scorched Earth Syndrome influences Mass Tourism Syndrome. In the second case - Infection - some of the active syndromes could 
precipitate another syndrome in the same region. The last one of the six forms of pairing is Succession, because syndromes connect with the historical development of the civilization.

\section{TRANSPORT WITHIN THE FRAME OF INDIVIDUAL SYNDROMES}

Transport, primarily road transport, is one of the symbols of the 20th century. Transport participates to a different extent in all of the syndromes. First of all it is connected to Urban Sprawl Syndrome and Smokestack Syndrome, but transport also impacts other syndromes. For example, transport vehicles used for extensive and indefensible agriculture can cause Rural Exodus Syndrome or Dust Bowl Syndrome. Military transport machines can cause Scorched Earth Syndrome. Also, additional syndromes, such as Asian Tigers Syndrome or Mass Tourism Syndrome, are not possible without transport. For example, the enhancement of the greenhouse effect by air travel is one of the major symptoms of Mass Tourism Syndrome.

The above-mentioned symptoms are the basic units for the description of the syndromes of global change. These symptoms characterize aspects of global dynamics, especially the relationship between civilization and nature. Presently the Concept includes 80 symptoms, for example, terrestrial run-off changes, increasing mobility or tropospheric pollution. Transport affects negatively our environment and participates in different symptoms. Figure 1 shows the connection between symptoms and transport.

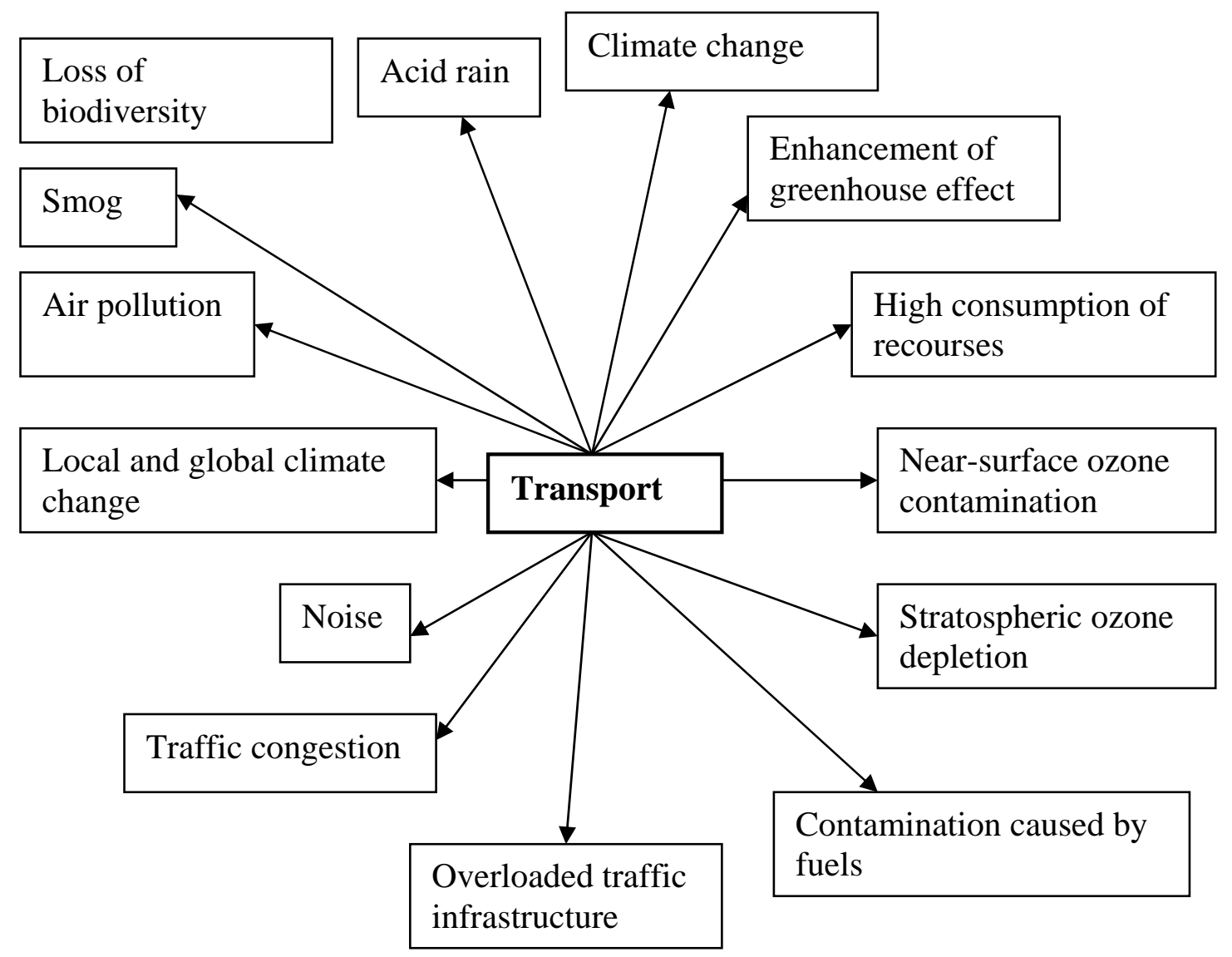

Figure 1: Symptoms and Transport. 
Transport has a particularly decisive influence in "Urban Sprawl Syndrome", and "Smokestack Syndrome". This contribution targets these especially. The both syndromes are connected, despite comprising of different groups of syndromes. Urban Sprawl Syndrome, also known as suburban sprawl, represents development syndromes, whereas Smokestack Syndrome represents the group of sink syndromes.

\subsection{Urban Sprawl Syndrome}

Urban Sprawl Syndrome means the spreading of residential, commercial and industrial zones around large cities, a typical example of which is Los Angeles, but this kind of syndrome begins to be typical also for the Czech Republic.

Urban Sprawl Syndrome contains lot of symptoms (WGBU, 1996):

- Air pollution

- Soil contamination

- Ozone contamination (near-surface and stratospheric)

- Fragmentation of ecosystems

- Acid rain

- Traffic congestion

- Enhanced greenhouse effect

These symptoms are caused largely by transport, a typical example of which is traffic congestion, or urban and air pollution.

One of the indicators of urban sprawl is a low population density. The low population density means a dependence on individual transport, and a dependence on individual transport brings with it a greater impact on the environment, for example, traffic jams or increasing emissions. Many different studies point to the link between petroleum consumption and urban density. For example, a study of more than 30 cities worldwide by Newman and Kenworthy (Newman \& Kenworthy, 1989) shows the relationship between petroleum use and average population density (see figure number 2 ).

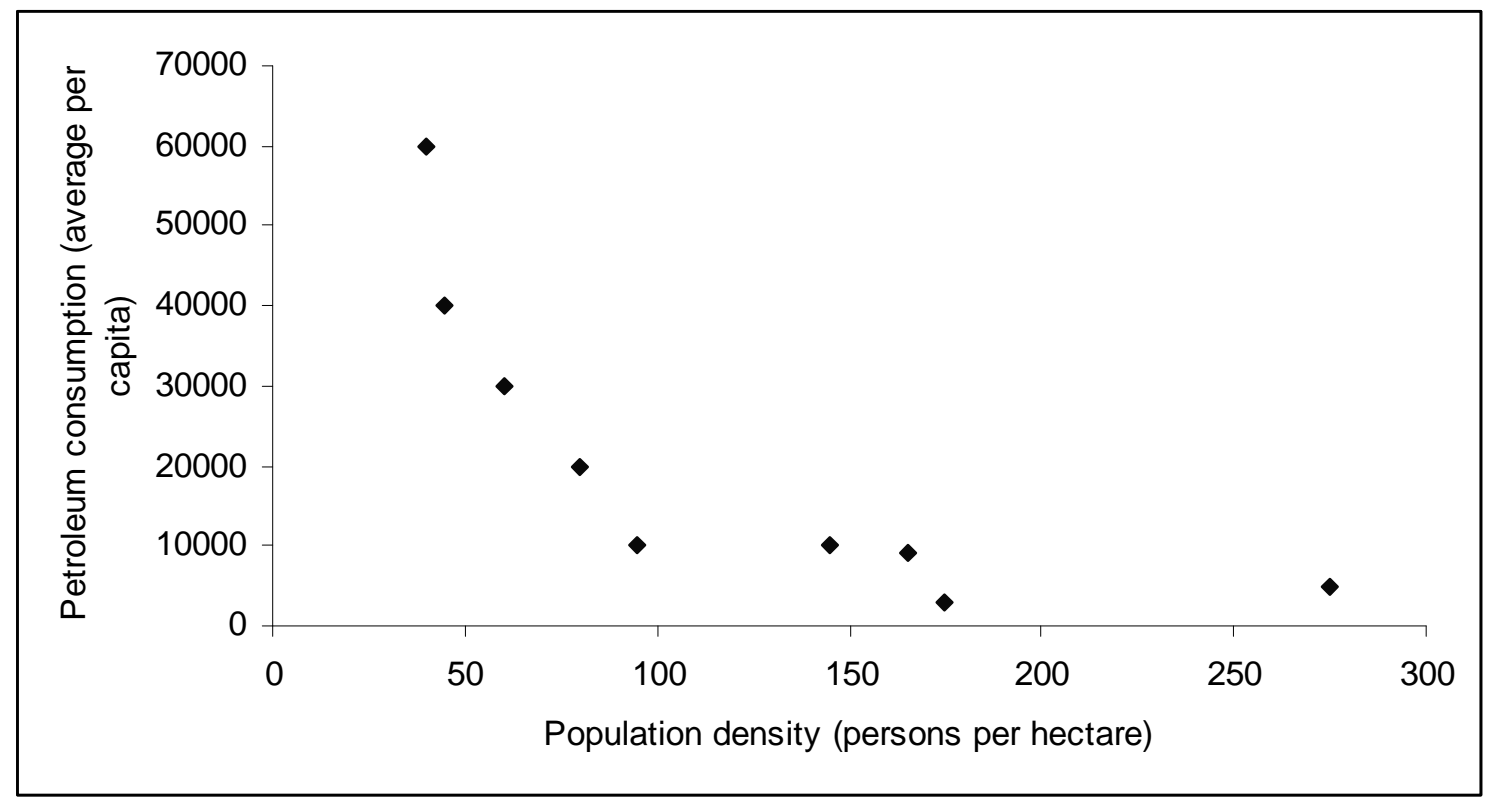

Figure 2: Relationships between petroleum use and average population density (Newman \& Kenworthy, 1989). 
This graph shows the fact that a low population density results in petroleum consumption rising. North American cities (primarily cities from the U.S.A., such as Los Angeles or Washington) are at the top of this curve. Canadian, and also Australian, cities (such as Toronto or Melbourne) are located below them. European cities (for example, Paris or London) lie in the middle of the graph. Asian cities (Tokyo, Singapore, Hong Kong) are on the bottom of this graph, because the population density is very high in this region.

\subsection{Smokestack Syndrome}

Smokestack Syndrome means environmental degradation through the large-scale diffusion of long-lived substances. Symptoms of Smokestack Syndrome contain these symptoms (WGBU, 1996):

- Attenuation of the stratospheric ozone

- Loss of biodiversity

- Regional and global climate change

- Sea level increasing

- Increasing of UV-B radiation

- Acid rain

- Contamination of soils and groundwater

- Enhanced greenhouse effect

- Eutrophication of ecosystems

These symptoms are the same as symptoms from Urban Sprawl Syndrome mainly caused by transport, for example, acid rain is a typical representative of regional impacts and an enhanced greenhouse effect is representative of the global impacts of transport on the environment.

According to emissions patterns and the physical-chemical characteristic it is possible to divide this group into three groups of activity. The first one is local, and the typical noxious substance in this group is dust. The second group - regional - creates $\mathrm{SO}_{2}, \mathrm{NO}_{\mathrm{x}}$ or $\mathrm{NH}_{3}$. These pollutants participate in, for example, acid rain. The third group - global - typically CFCs or $\mathrm{CO}_{2}$, causes global impacts, such as the greenhouse effect, and so on.

While the main sources of air pollution in cities were, in the past, industry and local heating, nowadays it is above all transportation. On the one hand, transportation increases the comfort of city inhabitants; on the other hand, it brings with it many problems air pollution being one of them. Transport belongs to the significant sources of emissions, and the participation of traffic, primarily road traffic, is considerable. Emissions from transport are included in the all of the three above-mentioned groups. A typical representative of the local group is particulate pollutants. The dust levels represent the negative impact of transportation, particularly in cities. Among the noxious substances from the second group produced by transport belong $\mathrm{NO}_{\mathrm{x}}$. The slightly increasing trend of air pollution by nitrogen oxides is mainly caused by an increasing share of road transportation. The third group transport is included with force $\mathrm{CO}_{2}$ emissions.

\section{CONCLUSION}

This contribution presents an interdisciplinary approach to the study of global change. Two of the syndromes that are related to transport are highlighted especially - Urban Sprawl Syndrome and Smokestack Syndrome.

Finally, the coherence between the Concept of the syndromes of global change and crucial environmental issues must be dropped. The graph on the figure 3 shows the link between 
the wo above-mentioned syndromes - Urban Sprawl Syndrome and Smokestack Syndrome and core problems with the environment.

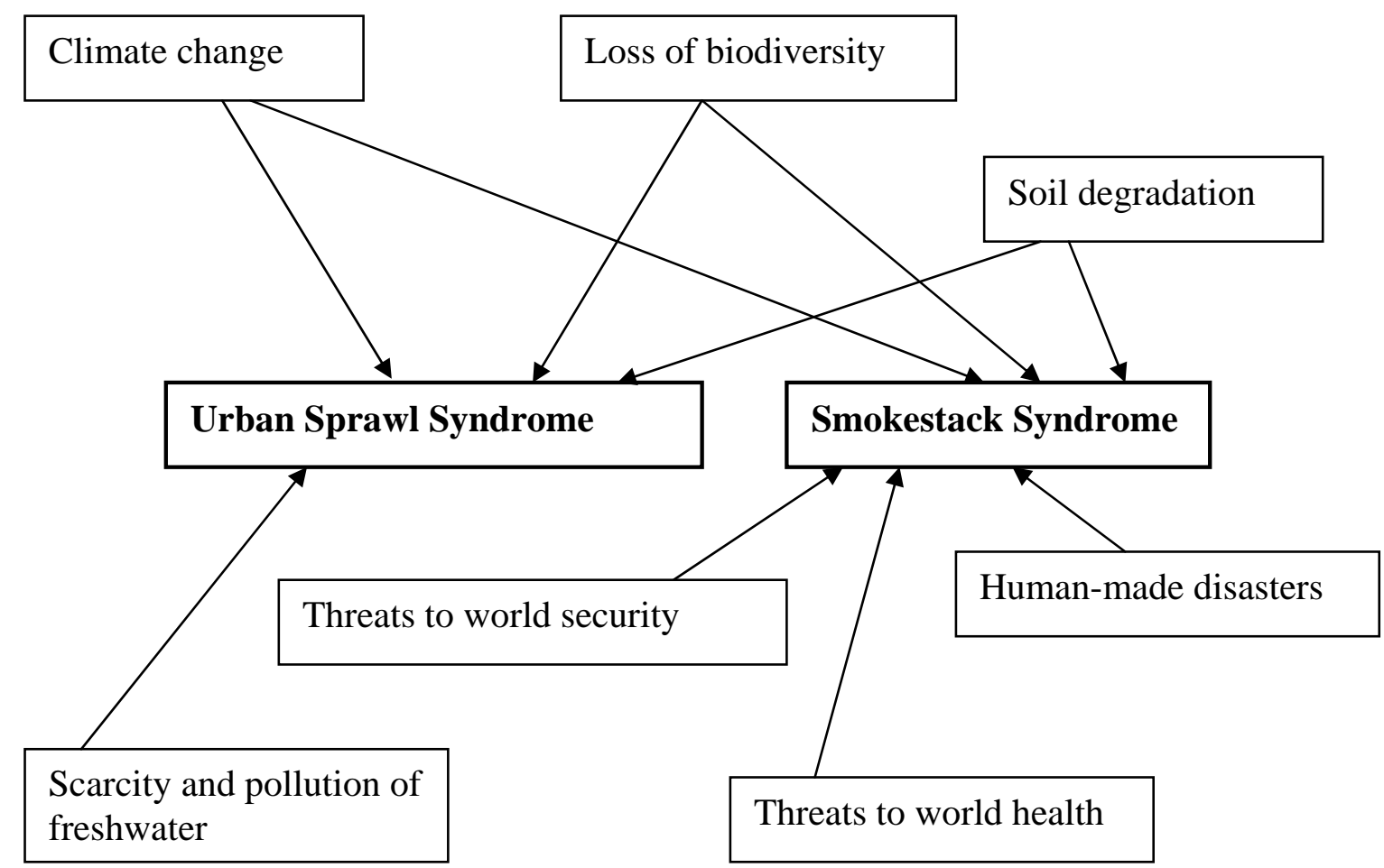

Figure 3: Syndromes and indicators of the core problems of environment (according to WGBU, 1996).

In conclusion is necessary to note that the Concept of the syndromes of global change is not over and research on this theory is still continuing.

\section{ACKNOWLEDGEMENTS}

This research has been supported by MSM 6840770043.

\section{REFERENCES}

German Advisory Council on Global Change (WGBU), 1996. World in transition: The research Challenge. Annual Report, Springer.

Newman, P., Kenworthy, J.,R., 1989. Gasoline consumption in cities: a comparison of US cities with global survey. Journal of American Planning Association, vol. 55, pp. 2437 Schellnhuber, H., J., et al. 1997. Syndromes of global change. GAIA, vol. 6, iss.1, pp.19-34.

Schröter, D., Polsky, C,. Patt, A., G., 2005. Assessing vulnerabilities to the effects of global change: an eight step approach. Mitigation and Adaptation Strategies for Global Change, vol. 10, iss. 4, pp. $573-595$.

Broennimann, O., Thuiller, W., Hughes, G., Midgley, G., F., Alkemades, J., M., R., Guisan, A., 2006. Do geographic distribution, niche property and life form explain plants' vulnerability to global change?Global Change Biology, vol. 12, iss. 6, pp. 1079 - 1093. 